\title{
Transmission of viral encephalopathy and retinopathy (VER) to yolk-sac larvae of the Atlantic halibut Hippoglossus hippoglossus: occurrence of nodavirus in various organs and a possible route of infection
}

\author{
Sindre Grotmol ${ }^{1, *}$, Øivind Bergh ${ }^{1}$, Geir K. Totland ${ }^{2}$ \\ ${ }^{1}$ Department of Aquaculture, Institute of Marine Research, PO Box 1870 Nordnes, N-5024 Bergen, Norway \\ ${ }^{2}$ Department of Zoology, University of Bergen, Allégt. 41, N-5007 Bergen, Norway
}

\begin{abstract}
The susceptibility of the Atlantic halibut Hippoglossus hippoglossus yolk-sac larvae to viral encephalopathy and retinopathy (VER) was investigated by waterborne challenge experiments with nodavirus. Transfer of VER was indicated by several lines of evidence. A significantly higher cumulative mortality was observed after challenge with virus compared to mock challenge, and increasing doses of virus resulted in shorter incubation periods. When the challenge was performed on the day after hatching, the time from inoculation to the time when $50 \%$ of the larvae were dead (LT 50 ) ranged from 26 to $32 \mathrm{~d}$. Postponement of challenge for $13 \mathrm{~d}$ reduced the $\mathrm{LT}_{50}$ to $14 \mathrm{~d}$, indicating that the susceptibility of the larvae to the present nodavirus strain was low during the first 2 wk after hatching The progression of the infection was monitored by sequential immunohistochemistry and electron microscopy. On Day 18 after hatching the initial signs of infection were observed as a prominent focus of immunolabelling in the caudal part of the brain stem. In the same larvae immunolabelled single cell lesions were observed in the stratified epithelium of the cranial part of the intestine. The portal of entry into the larvae may thus have been the intestinal epithelium, while the route of infection to the CNS may have been axonal transport to the brain stem through cranial nerves such as the vagus nerves. Later in the infection, lesions became more severe and widespread and were also found throughout the brain and spinal cord and in the retina, cranial ganglia, intestine, liver, olfactory epithelium, yolk-sac epithelium, gills and pectoral fins. The mortality in all virus-challenged groups was $100 \%$. This study thus demonstrates that the present nodavirus strain is able to replicate and cause VER in Atlantic halibut yolk-sac larvae at temperatures as low as $6^{\circ} \mathrm{C}$
\end{abstract}

KEY WORDS: Viral encephalopathy and retinopathy (VER) - Nodavirus · Atlantic halibut - Pathogenesis - Immunohistochemistry · Electron microscopy

\section{INTRODUCTION}

Nodaviruses are major pathogens of marine teleost larvae and cause devastating disease in at least 20 cultured species (Munday \& Nakai 1997, Song et al. 1997). High mortalities are most frequently observed in larvae and juvenile fish, but the disease has also caused severe losses in adult sevenband grouper Epi-

•E-mail: sindre.grotmol@imr.no nephelus septemfasciatus (Fukuda et al. 1996) and European sea bass Dicentrarchus labrax (Le Breton et al. 1997).

The disease caused by fish nodavirus has variously been termed fish encephalitis (Bellance \& Gallet de Saint-Aurin 1988), viral nervous necrosis (VNN) (Yoshikoshi \& Inoue 1990), encephalomyelitis (Bloch et al. 1991), and viral encephalopathy and retinopathy (VER) (Munday et al. 1992). In the present study it will be referred to as VER 
VER is characterised by neurological symptoms related to disturbed equilibrium, failure of muscular control and visual dysfunction. Common clinical signs are lack of appetite, changes in pigmentation, hyperinflation of the gas bladder and abnormal swimming behaviour including hyperreactivity with uncoordinated darting, rolling and pitching. The signs are most apparent in juveniles and adult fish. Gross pathological changes are uncommon. Microscopical lesions, however, are easily detected and are characterised by cellular vacuolation and neuronal degeneration in the central nervous system (CNS) and the retina. The causative viruses have been purified from diseased larvae of striped jack Pseudocaranx dentex (Mori et al. 1992), European sea bass and barramundi Lates calcarifer (Comps et al. 1994), and the agent from European sea bass has also been propagated in cell cultures (Frericks et al. 1996, Delsert et al. 1997).

Natural infections of nodavirus in marine fish occur in a wide range of water temperatures. Most of the affected fish are warmwater species with optimal rearing temperatures between 20 and $30^{\circ} \mathrm{C}$. Nodavirus infections have also been reported in cold-water species such as the barfin flounder Verasper moseri (Anonymous 1995) and the Atlantic halibut Hippoglossus hippoglossus (Grotmol et al. 1997). However, transmission of fish nodaviruses has only been demonstrated experimentally in warmwater teleosts.

The disease has been transmitted by cohabitation in barramundi (Glazebrook et al. 1990) and to juveniles of redspotted grouper Epinephelus akara by both intraperitoneal injection and waterborne challenge with homogenates from diseased fish (Mori et al. 1991). In striped jack larvae the infection has been transmitted by both waterborne challenge and cohabitation (Arimoto et al. 1993). VER has also been transferred to juveniles of Japanese flounder Paralichthys olivaceus by waterborne challenge with homogenates of diseased fish (Nguyen et al. 1994). Brownspotted grouper Epinephelus malabaricus developed the disease after injection of a homogenate of brains and eyes from diseased fish (Danayadol et al. 1995, Boonyarathpalin et al. 1996). Transmission to European sea bass juveniles by intramuscular injection of infectious homogenate has also been demonstrated (Thiery et al. 1997). Waterborne challenge and intramuscular inoculation on sevenband grouper and redspotted grouper (Tanaka et al. 1998) demonstrated that the pathogenicity of the nodavirus increased with rising water temperature.

The progression of VER has been studied in naturally and experimentally infected striped jack larvae (Nguyen et al. 1996) but the route of infection was unclear. Viral replication was first observed in the skin and spinal cord, particularly in the area above the gas bladder, later in the brain, and then in the retina.
In contrast, the pathogenicity of nodavirus to the Atlantic halibut has not been experimentally demonstrated. The Atlantic halibut is adapted to cold water and the optimal temperature for the yolk-sac larvae is between 5 and $7^{\circ} \mathrm{C}$ (Pittman et al. 1990). The larvae hatch at an earlier developmental stage than most other teleost fish, and the newly hatched halibut larvae lack pigments, functional eyes and mouth. Both the cold-water environment and the early developmental stage at hatching may influence the pathogenesis of VER.

The prime aim of the present study was to test if VER was transferable to newly hatched yolk-sac larvae. We also wished to study the pathogenesis of the disease by monitoring the distribution of nodavirus and development of lesions in the larvae during the incubation period in an attempt to unravel the route of infection.

\section{MATERIALS AND METHODS}

Eggs and larvae. Three separate batches of eggs and sperm were obtained by stripping 3 females and 3 males of the wild-caught broodstock at Austevoll Aquaculture Research Station (Norway). The eggs of each batch were mixed with sperm from 1 of the males, and the fertilisation rate was above $95 \%$ in all batches. Until the experiments began, the eggs were reared in $250 \mathrm{l}$ up-welling incubators at 6 to $7^{\circ} \mathrm{C}$, as described by Pittman et al. (1990).

The presence of nodavirus in 20 larvae from each egg batch was tested using a reverse transcriptase polymerase chain reaction (RT-PCR) (Nishizawa et al. 1994). RT-PCR amplification using the $R_{3}$ and $F_{2}$ primers was negative.

Materials for virus and mock challenge. Atlantic halibut larvae and juveniles were collected during episodes of acute high mortality in 2 commercial hatcheries. The specimens were stored frozen at $-80^{\circ} \mathrm{C}$. Histopathological and electronmicroscopical examinations of the larvae revealed viral encephalopathy and retinopathy associated with a nodavirus-like agent as described by Grotmol et al. (1997).

An infectious homogenate (I) from the Atlantic halibut with VER was prepared according to the following procedure: $2 \mathrm{~g}$ of tissue, consisting of the eyes, crania and vertebral columns, was homogenised in a $10 \mathrm{ml}$ Potter-Elvehjems tissue grinder with $10 \mathrm{ml}$ sterile $0.9 \%$ $\mathrm{NaCl}$ (aq). The homogenate was cleared by centrifugation at $3000 \times g$ for $20 \mathrm{~min}$ at $4^{\circ} \mathrm{C}$, and the supernatant was filtered through a membrane with a pore size of $220 \mathrm{~nm}$. It was not possible to obtain Atlantic halibut juveniles that were uninfected with nodavirus, and for the mock challenge a homogenate (M) of healthy salmon fry was produced according to the same proto- 
col as employed with the infectious material. The presence of nodavirus in the homogenates was tested for by RT-PCR and a single product of approximately 430 base pairs ( $\mathrm{T}_{4}$ region) was generated when the reaction was performed on the infectious homogenate. RT-PCR on the homogenate for mock challenge was negative. Cultures of Chinook salmon embryo cells (CHSE-214) were inoculated with the homogenates and no cytopathic effect was observed after 2 passages. Both homogenates were applied undiluted (I, M), and diluted 10-fold (I-10, M-10) and 100-fold (1-100, M-100) in sterile $0.9 \% \mathrm{NaCl}$ (aq).

Rearing conditions. The halibut eggs and larvae were kept in complete darkness in a climate-regulated room at $6^{\circ} \mathrm{C}$. During periods of rearing and observation, the room was illuminated by a dim red light (2.5 lux). The eggs and larvae were incubated in polystyrene 6-well tissue-culture plates (Multidish 6, Nunc, Roskilde, Denmark). The wells had a diameter of $35 \mathrm{~mm}$ and a depth of $18 \mathrm{~mm}$. Six days prior to hatching the wells were filled with $10 \mathrm{ml}$ autoclaved, diluted sea water ( $25 \%$ salinity), and a single egg was transferred to each well (Bergh et al. 1992). The mortality at the egg stage was $4.2,3.8$ and $3.2 \%$ in the 3 batches.

Day 0 was defined as the day on which at least $50 \%$ of the eggs had hatched. On the following day (Day 1), $9 \mathrm{ml}$ of water was removed from each well together with debris of the eggshell and replaced with fresh autoclaved diluted sea water (25\% salinity). The 6 -well plates were randomised and divided into the experimental groups.

Infection trials. Three infection trials were performed: Trial I: The first trial consisted of 7 groups. Three groups were challenged with different concentrations of nodavirus: Group I with undiluted infectious Atlantic halibut homogenate (I), Groups I-10 and I-100 with 10 -fold and 100-fold diluted infectious homogenate, respectively. Three groups were used for mock challenge and each group was challenged with 1 of the 3 different solutions of salmon fry homogenate (M, M-10, M-100). One group (C) was left unchallenged. On Day 1 the larvae were challenged by adding $100 \mu \mathrm{l}$ of the designated homogenate to the water in each well. Each group consisted of 130 larvae. Sixty larvae were used exclusively for mortality registration, while samples for immunohistochemistry and histopathology were taken from the remaining 70 . The mortality was recorded every second day until Day 52 and living larvae (also moribund) were sampled randomly from each group after the rise in the mortality rate.

Trial II: The second trial consisted of 3 groups. In Group I each larva was challenged with undiluted infectious Atlantic halibut homogenate, while the larvae of Group $M$ were mock challenged with undiluted homogenate of healthy salmon fry and 1 group was left unchallenged. On Day 1 the larvae were challenged by adding $100 \mu l$ of designated homogenate to the water in each well. Each group consisted of 300 larvae. Sixty larvae were used exclusively for mortality registration, while samples for light and electron microscopy were taken from the remaining 240. Mortality was recorded every second day until Day 52. On Days 12 and 18 and every second day thereafter 15 living larvae (also moribund) were sampled randomly for histological and immunohistochemical examinations, and 5 for electron microscopy. For testing with RT-PCR, 5 newly dead larvae from each group were sampled and stored frozen $\left(-80^{\circ} \mathrm{C}\right)$

Trial III: The third trial was comprised of 3 groups, each consisting of 60 larvae. One group (I-13) was challenged on Day 13 with an infectious homogenate, while the larvae of Group M-13 were mock-challenged at the same point of time. The control group C-13 was left unchallenged. The challenge was performed by adding $100 \mu$ l of designated homogenate to the water in each well. A total of 15 moribund larvae were sampled randomly from each group for immunohistochemistry.

Clinical signs and mortality. Mortality and clinical signs were recorded every second day. Larvae were defined as dead when they had lost their normal transparency and appeared grey, opaque and shrunken. Differences in mortality were checked for statistical significance by the chi-square contingency table test, assuming a binominal distribution of the data (Zar 1984).

Tissue preparation. Sample processing for light microscopy: From Trial I, 10 larvae from each group, collected during periods with a high mortality rate, were examined. From Trial II, 5 to 15 larvae were examined from each group at each sampling. From all larvae multiple sections including brain, spinal cord, retina, heart, gills and abdominal organs were examined.

Fixation, embedding and staining: Samples were fixed for $24 \mathrm{~h}$ in neutral phosphate-buffered $10 \%$ formalin, dehydrated through a graded ethanol series and embedded in paraffin. Sections, $3 \mu \mathrm{m}$ thick, were cut on a Reichert-Jung Biocut, incubated for $30 \mathrm{~min}$ at $56^{\circ} \mathrm{C}$, dewaxed in xylene, rehydrated through a graded ethanol series, brought to distilled water and finally stained with haematoxylin/eosin/saffron (HES) and examined by light microscopy.

Immunohistochemistry: All specimens stained with HES were also processed for immunohistochemistry. Nodavirus were detected by an avidin-biotin-alkalinephosphatase complex ( $\mathrm{ABC} / \mathrm{AB})$ immunohistochemical technique modified from $\mathrm{Hsu}$ et al. (1981) and Evensen (1993). The primary antiserum was raised in 
rabbit against a recombinant coat protein encoded by the $\mathrm{T} 2$ region of the RNA2 of the striped jack nervous necrosis virus. Sections of formalin-fixed paraffinembedded Atlantic halibut tissue were deparaffinized at 58 to $59^{\circ} \mathrm{C}$ for $30 \mathrm{~min}$, washed in 2 xylene baths and rehydrated through a series of decreasing concentrations of ethanol $(100 \%, 96 \%, 70 \%, 50 \%)$. Nonspecific antibody binding sites were blocked by covering the sections with a solution of $5 \%$ bovine serum albumin (BSA) in Tris-buffered saline (TBS, pH 7.4) for $20 \mathrm{~min}$. The solution was blotted off the slides and the primary rabbit antiserum was incubated at a dilution of 1:900 in $2.5 \% \mathrm{BSA}$ in TBS for $30 \mathrm{~min}$. After washing for $5 \mathrm{~min}$ in TBS, the secondary antibody, biotinylated goat antirabbit immunoglobulin, diluted $1: 300$ in $2.5 \% \mathrm{BSA}$ in TBS (Dakopatts, Glostrup, Denmark), was added and incubated for $30 \mathrm{~min}$. After washing in TBS, streptavidin alkaline phosphatase complex (diluted 1:1000; Boehringer, Darmstadt, Germany) was added and incubated at room temperature for $30 \mathrm{~min}$. After washing, New Fuchsin Chromogen (K698, Dako, CA, USA) with $1 \mathrm{mM}$ levamisole (Sigma Co., London, UK) as inhibitor in TBS was added and allowed to develop for 5 min. After washing in tap water, sections were counterstained with Mayer's haematoxylin and mounted in an aqueous mounting mediun (Aquamount; BDH Laboratory Supplies, UK).

All incubations were performed at room temperature in a humidity chamber. Tissue sections from all viruschallenged, mock-challenged and unchallenged groups were incubated with immune and nonimmune serum (normal rabbit serum). The endpoint dilutions of the primary antibody that gave an immunolabeling discernible from background were determined after $30 \mathrm{~min}$ incubation at room temperature (Petrusz 1983).

Sample processing for electron microscopy: For transmission electron microscopy whole larvae were submerged in fixative for at least $24 \mathrm{~h}$ and then dissected under a binocular microscope into 3 pieces; head, trunk and tail part. A volume of $100 \mathrm{ml}$ fixative was composed of $10 \mathrm{ml} 10 \%$ formaldehyde (freshly prepared from paraformaldehyde), $10 \mathrm{ml} 25 \%$ glutaraldehyde, $20 \mathrm{ml} 0.2 \mathrm{M}$ cacodylate buffer and $60 \mathrm{ml}$ PBS $(\mathrm{pH} 7.35)$. After this primary fixation, the specimens were rinsed in buffer and postfixed in $1 \% \mathrm{OsO}_{4}$, dehydrated in ethanol and embedded in Epon 812 (Fluka Chemie AG, Switzerland). Semithin sections (1 $\mu \mathrm{m}$ thick) for light microscopy were stained with a solution of toluidine blue. Ultrathin sections were contrasted in uranyl acetate and lead citrate and observed in a JEOL CX 100 transmission electron microscope.

$R T-P C R$ for detection of nodavirus: The presence of nodavirus in 5 larvae from each group of Trial II was tested using RT-PCR by complying to the protocol of Nishizawa et al. (1994).

\section{RESULTS}

\section{Clinical signs and mortality}

The initial clinical sign was that larvae ceased swimming and were usually found lying on their sides with an abnormal ventral convexity (lordosis) of the vertebral column. These signs were common from Day 16 onwards. Furthermore, from Day 25 prominent dark granules appeared in the dorsal portion of the yolk sac. The size of these granules increased towards the terminal stage.

The cumulative mortality curves for Trial I are shown in Fig. 1, and those of Trials II and III are shown in Fig. 2. In Trial $I$, the length of the incubation period varied in response to the dose of virus. The cumulative mortality in the 3 groups exposed to different concentrations of nodavirus (I, I-10, I-100) rose to $100 \%$ following a steep, sigmoid curve during the fourth and fifth week after challenge. Statistical covariation analysis showed that Group I was significantly different from the other groups from Day 26 after challenge onwards, Group I-10 from Day 28 and Group I-100 from Day 32 ( $p<0.001)$. The time from inoculation to $50 \%$ cumulative mortality $\left(\mathrm{LT}_{50}\right.$ ) for Group I was $26 \mathrm{~d}$, and dilution of the infectious homogenate, 10- and 100 -fold, resulted in a delay in $\mathrm{LT}_{50}$ by 3 and $6 \mathrm{~d}$, respectively (Fig. 1). In the mock-challenged groups and in the unchallenged group there were insignificant differences in mortality. The onset of mortality in the 3 mock-challenged groups and in the unchallenged group was approximately 1 wk later than in the I-100 group. The $\mathrm{LT}_{50}$ s of the unchallenged group and the mock-challenged groups were 37 to $42 \mathrm{~d}$. The cumulative mortality of these groups varied from 70 to $80 \%$ on Day 52 , when the experiment was terminated,

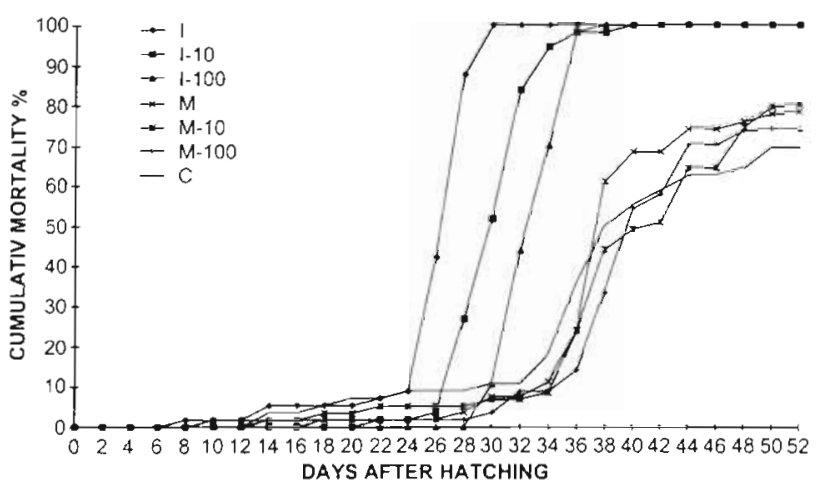

Fig. 1. Cumulative mortality curves of Trial I. Groups I, I-10 and I-100 were exposed to nodavirus by waterborne challenge using undiluted, 10- and 100-fold dilutions of infectious homogenate, resepectively. Groups M, M-10 and M- 100 were mock-challenged, while Group $C$ was left unchallenged. Challenge was performed on Day 1 after hatching 


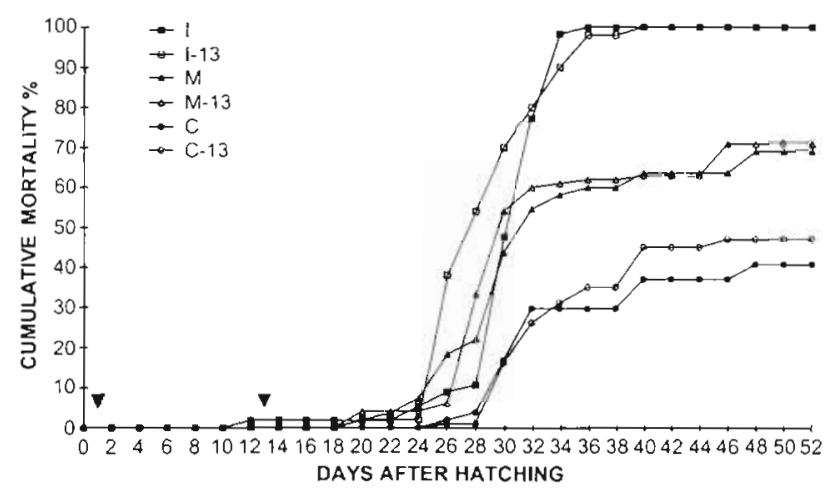

Fig. 2. Cumulative mortality curves of Trials II and III. In Trial II, Group I was exposed to nodavirus by waterborne challenge using an infectious homogenate. Group $M$ was mock-challenged, while Group $C$ was left unchallenged. In Trial II inoculation was performed on Day 1 (shaded arrowhead). Trial III was designed as Trial II (infected group: I-13, mock-challenge group: $\mathrm{M}-13$ and control group: C-13), except for the point of time of the challenge, which was performed on Day 13 (black arrowhead). Note the similar cumulative mortality curves of Trials II and III in spite of the different time points of inoculation

whereas in all the challenged groups, mortality had reached $100 \%$ by Day 40 .

In the second infection trial, the $\mathrm{LT}_{50}$ of the group challenged with the infectious homogenate (I) was $30 \mathrm{~d}$, reaching 100\% mortality $2 \mathrm{~d}$ later (Fig. 2). The $\mathrm{LT}_{50}$ for the mock-challenged group was $31 \mathrm{~d}$ and a maximum cumulative mortality of $68 \%$ was reached after $48 \mathrm{~d}$. These groups displayed similar mortality patterns until Day 32, after which the group challenged with infectious homogenate was significantly different and showed higher mortality than the mockchallenged group ( $p<0.001)$, while both groups suffered significantly higher mortality than the unchallenged control group ( $p<0.001)$. In the unchallenged group the maximum cumulative mortality (40\%) was reached after $48 \mathrm{~d}$ of trial.

In Trial III the postponement of challenge until Day 13 resulted in a reduction of $\mathrm{LT}_{50}$ to $14 \mathrm{~d}$ in the group challenged with infectious homogenate. In spite of the postponed inoculation the cumulative mortality curves were closely similar to those of Trials I and II (Fig. 2).

\section{Histopathology and detection of virus}

Nodavirus was only detected in the larvae exposed to infectious homogenate, and all fish sampled on Day 18 and onwards showed lesions associated with nodavirus infection. Immunolabelling was first observed in single cells or small foci, and in the later stages these tissues developed diffuse lesions. Aggregations of spherical unenveloped virus particles with diameters of approximately $25 \mathrm{~nm}$ were observed in the lesions and the morphology of the virions was identical to that observed in the infectious material (Figs. 3, $4 \& 5$ ).

\section{Nervous tissue and sensory organs}

Examinations of larvae sampled $12 \mathrm{~d}$ after hatching revealed neither lesions nor the presence of aggregated virus particles in nervous tissue. The initial immunolabelling of nervous tissue was observed on Day 18 in the CNS (Figs. 6 \& 7) and cranial ganglia adjacent to the otic capsule (Fig. 12). In most larvae a prominent focus of infection was the ventrolateral grey matter of the caudal brain stem (Fig. 6). In addition, small groups of immunolabelled neurons or neurogenic cells were observed in the cranial grey matter of the spinal cord (Figs. 6 \& 7). In some of the larvae immunolabelled single cells were also found scattered in the more caudal part of the spinal cord and in the cranial brain stem (Fig. 6). On Day 20 after hatching, the infection had spread in cranial and caudal directions and had caused diffuse lesions in both the brain stem (Fig. 8) and the spinal cord (Fig. 9). A small number of scattered vacuoles in the brain stem and spinal cord appeared from Day 20. From Day 24 and onwards, most parts of the brain, except the various growth zones, had characteristic lesions with diffuse immunolabelling (Fig. 10). At this stage most tissue of the spinal cord showed severe diffuse lesions (Fig. 11). Within these lesions most of the cells were necrotic with pycnotic nuclei and numerous vacuoles could be observed (Fig. 11). In the retina, immunolabelling was first detected on Day 20 after hatching. By Day 28 the retina of most larvae were affected and the infection had spread to most cells within the ganglionic and bipolar layers, except for the growth zone at the ora serrata (Fig. 13). By Day 26 immunolabelling was observed in the olfactory epithelium (Fig. 14) and on Day 30 the macula of the utriculus showed immunolabelling.

Electron microscopy revealed cellular lesions in neurons and neurogenic cells of the CNS from Day 18 , in the craniospinal ganglia from Day 20 and in the retina from Day 28. Affected cells contained nodavirus-like particles with diameters of approximately $25 \mathrm{~nm}$ (Fig. 4) and the virions were either found as semicrystalline arrays or single cytoplasmic particles. The mitochondria were degenerate; the cisterna of the endoplasmatic reticulum were distended or vacuolated (Fig. 3) and were often studded with virus. The plasma membranes of infected cells were more or less completely covered with regularly spaced virions (Figs. 4 \& 5). Some cells appeared dark (electron-dense), with their cytoplasm completely replaced by a densely packed viral matrix (Fig. 3) 


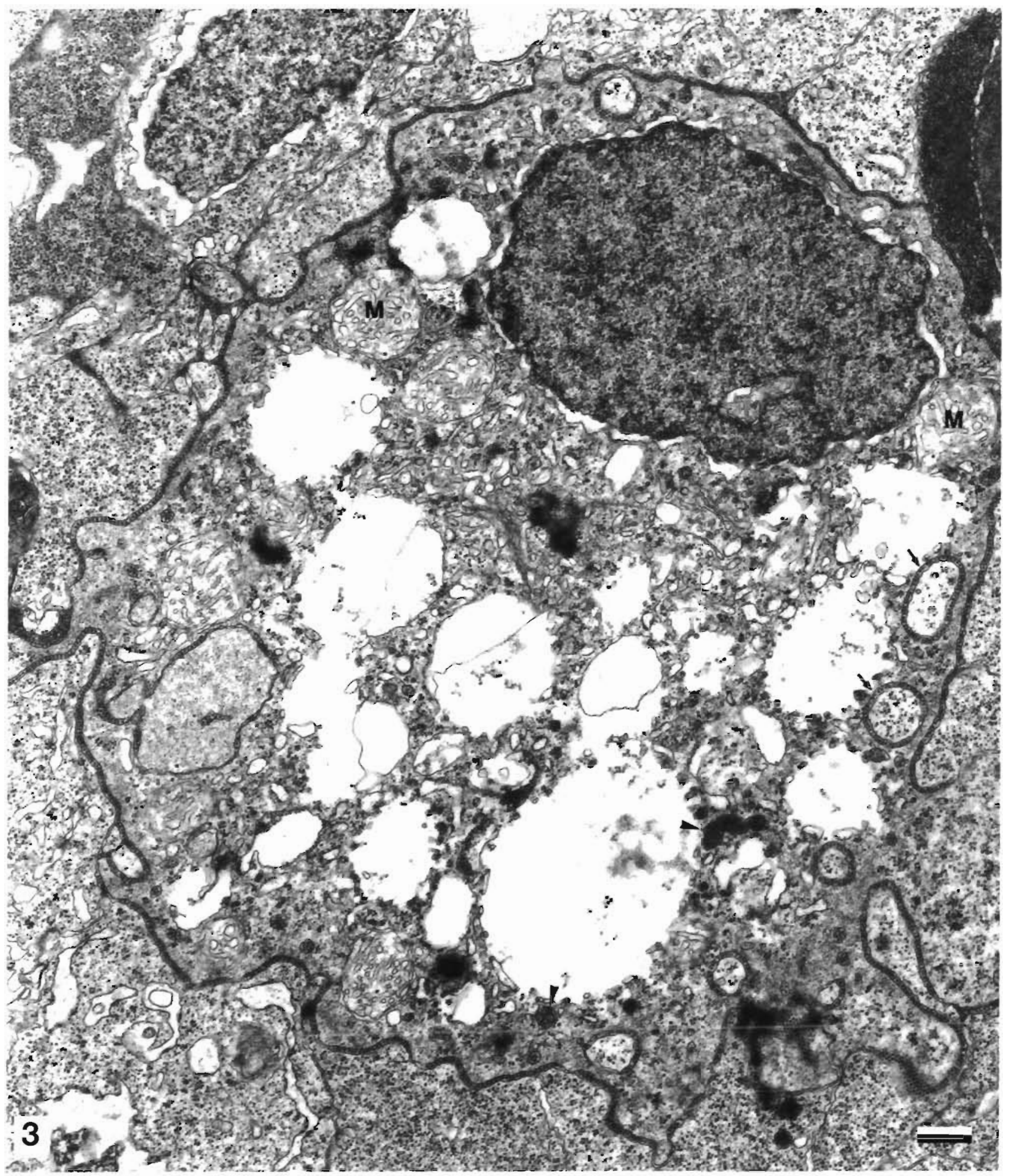

Fig. 3 Hippoglossus hippoglossus. Electron micrograph of nervous tıssue. Bram Virus-infected cell from the cranial brain stem. Some cisterna of the endoplasmic reticulum are distended, forming small vacuoles The degenerate mitochondria are swollen with distorted cnstae (M). Virus partıcles are found free in the cytoplasm and as membrane-bound aggregates (arrowheads). Note the monolayer of evenly spaced virions completely surrounding the cell occupying the intercellular space. In invaginated regions of adjacent cells the virus monolayer and the plasma membranes form ball bearing-like structures (arrows). A part of an electron-dense cell where most of the cytoplasm has been replaced by vinons is shown in the upper right-hand corner. 

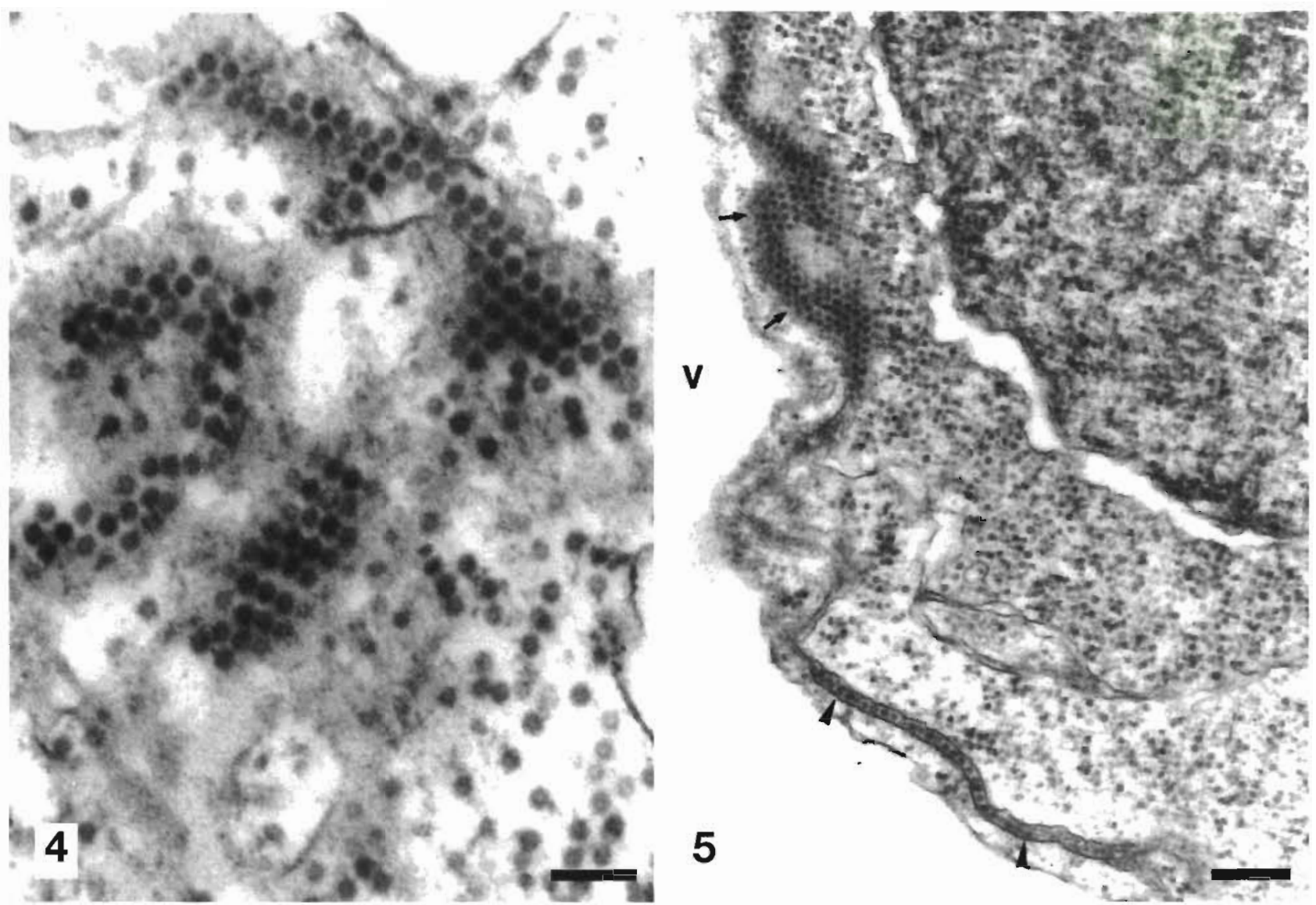

Figs. 4 \& 5. Hippoglossus hippoglossus. Electron micrographs of nervous tissue. Fig 4 . Brain. High-power micrograph of a cytoplasmic semicrystalline aggregate of nodavirus-like particles. Scale bar $=0.1 \mu \mathrm{m}$. Fig. 5 . Brain. High-power micrograph of region between 2 adjacent cells, one of them containing a vacuole ( $V$ ). Note the evenly distributed virions in a necklace-like pattern in the intercellular space (arrowheads). Where the intercellular space is tangentially sectioned (arrows), the evenly spaced viral monolayer is evident. Scale bar $=0.25 \mu \mathrm{m}$

\section{Digestive system}

On Day 18, concurrent with the appearance of immunolabelling in nervous tissue, immunolabelled vacuolated single cells were also found in the stratified epithelium of the cranial part of the intestine, presumably the esophagus anlage (Figs. 6 \& 15). By Day 28 the lesions had increased and multifocal necrosis of the epithelium containing large vacuoles were observed (Fig. 16); in some fish these lesions were severe (Fig. 17) covering larger areas. In addition, smaller immunolabelled focal lesions were also found in the the wall of the middle part of the intestine (Fig. 18). On Day 26 immunolabelling appeared in lesions in the craniodorsal quadrant of the yolk sac (Figs, 10 \& 19), presumably corresponding to the dark granules observed by the naked eye in the living larvae at this stage. The immunolabelling was confined to areas with swollen degenerated yolk-sac epithelium (Fig. 19). In the liver, multifocal immunolabelled lesions were observed from Day 20. These consisted of necrosis of single or small groups of hepatocytes (Fig. 20) often accompanied by vacuolation

Integument and musculature

By Day 20 multifocal immunolabelling was observed in the epidermis and in the epithelium of the gill arches (Fig. 21) and scattered, single virus-like particles were observed by electron microscopy in the epidermis (not shown). Mesodermal cells of both the gill arches and pectoral fin bud were immunolabelled (Figs. 21 \& 22) and at this stage immunolabelling was also found in scattered degenerate muscle fibers and multifocally within the myosepta of the axial musculature (not shown). 

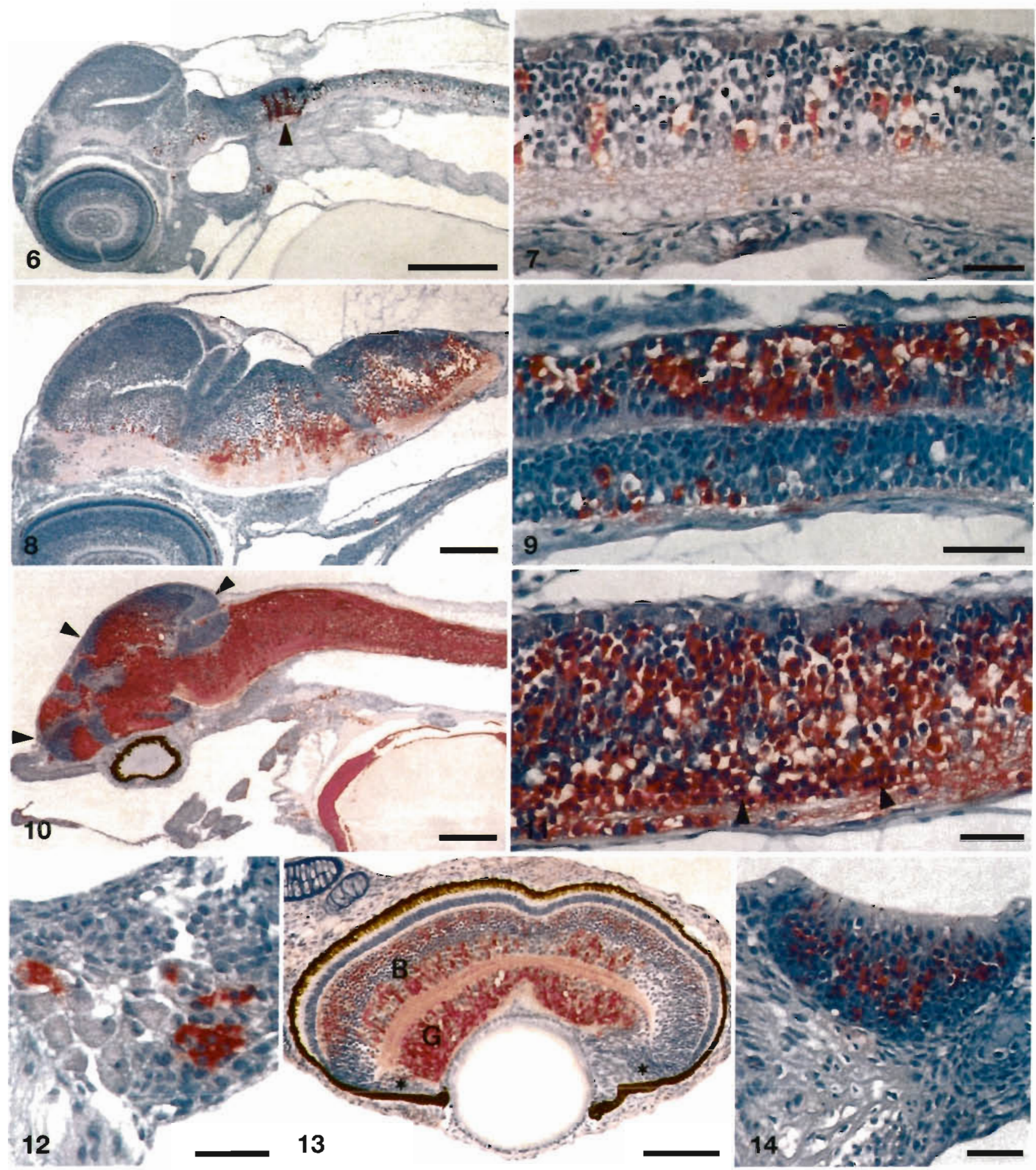

Figs. 6 to 14. Hippoglossus hippoglossus. Immunohistochemical staining of paraffin sections. Avidin biotin alkaline phosphatase method, anti-recombinant Striped jack nervous necrosis virus (SJNNV) coat protein serum and Mayer's haematoxylin counterstain. Fig. 6. Brain and spinal chord. Larva from Day 18 after challenge. Note the prominent focal immunolabelling in the ventral part of the caudal brain stem (arrowhead) and the smaller foci in the crainal brain stem and spinal cord. Immunolabelling of the cranial region of the intestinal anlage is also evident. Scale bar $=100 \mu \mathrm{m}$. Fig. 7. Spinal chord. Larva from Day 18. Focal immunolabelling of single cells. Scale bar $=5 \mu \mathrm{m}$. Fig. 8. Brain. Larva from Day 22. Diffuse lesions were found in the brain stem. Scale bar $=40 \mu \mathrm{m}$. Fig. 9. Spinal cord. Larva from Day 22. Diffuse lesions and vacuoles can be observed. Scale bar $=10 \mu \mathrm{m}$. Fig. 10. Brain and spinal cord. Larva from Day 26 showing widespread, diffuse immunolabelling of the brain and spinal cord. Note the absence of immunolabelling in the growth zones (arrowheads). Scale bar $=100 \mu \mathrm{m}$. Fig. 11. Spinal cord. Larva from Day 26 showing diffuse neuronal degeneration and immunolabelling. Note the prominent pycnosis (arrowheads). Scale bar $=5 \mu$ m. Fig. 12 . Ganglionic cells adjacent to the otic capsule $(O C)$. Early immunolabelling was detected in this region. Scale bar $=10 \mu \mathrm{m}$. Fig. 13 . Eye Retina in late stage of infection (Day 30). Note the prominent immunolabelling in both the bipolar (B) and ganglionic cell layers (G). Note the absence of immunolabeling in the growth zone of the ora serrata ( $*$ ). Scale bar $=30 \mu \mathrm{m}$. Fig. 14, Olfactory epithelium in late stage of infection (Day 28). Note the immunolabelling of the sensory epithelium. Scale bar $=10 \mu \mathrm{m}$ 


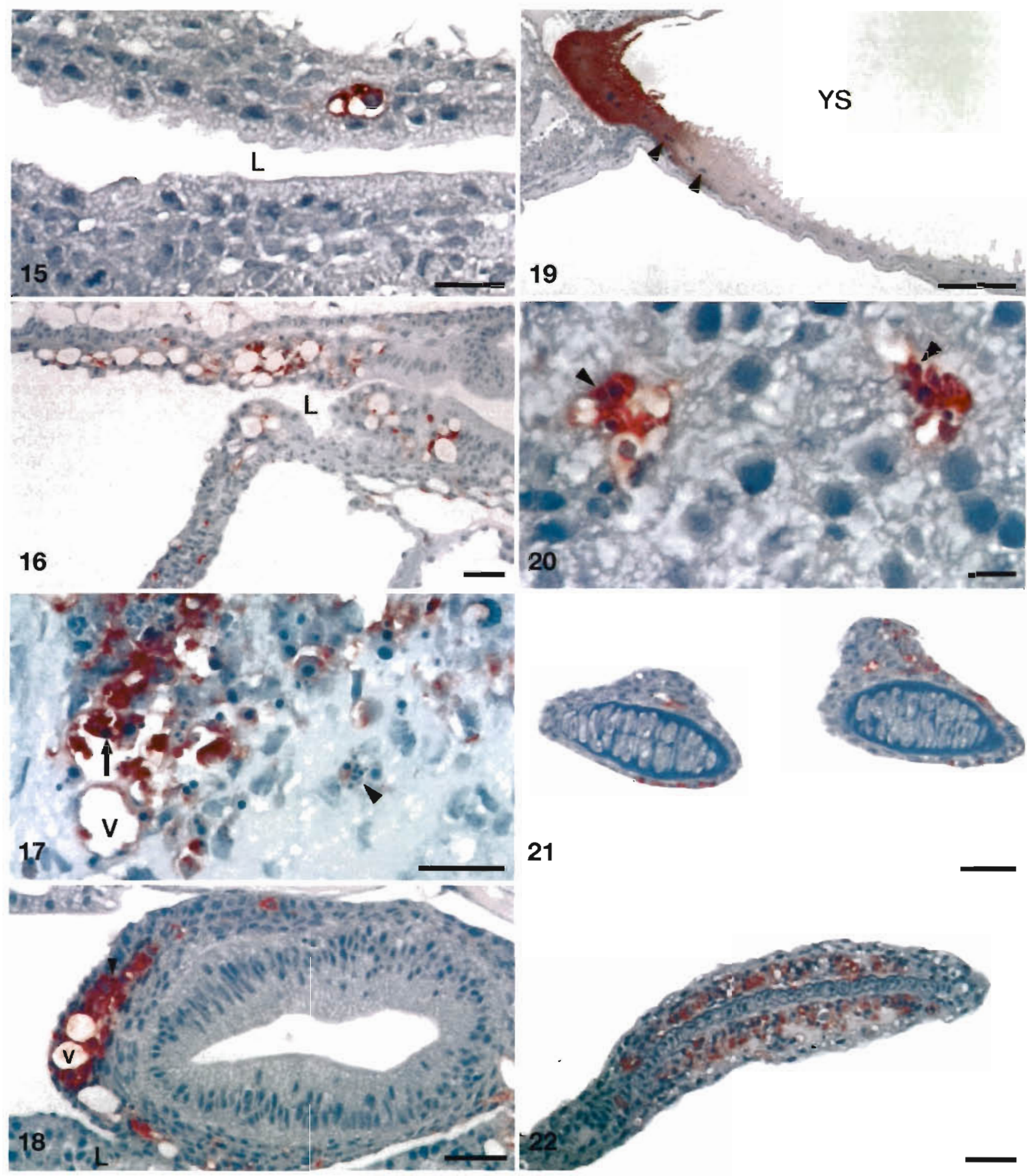

Figs. 15 to 22. Hippoglossus hippoglossus. Immunohistochemical staining of paraffin sections. Avidin biotin alkaline phosphatase method, anti-recombinant SJNNV coat protein serum and Mayer's haematoxylin counterstain. Fig. 15. Cranial part of the intestine of larva sampled on Day 18 after hatching. Some cells of the epithelium contain vacuoles and are immunolabelled. $\mathrm{L}=$ lumen of the intestine. Scale bar $=3 \mu \mathrm{m}$. Fig. 16. Cranial part of the intestine of larva from Day 22. At this stage the epithelium showed diffuse lesions with numerous immunolabelled vacuolated cells. $L=$ lumen of the intestine. Scale bar $=10 \mu \mathrm{m}$. Fig. 17 . Severe diffuse necrotic lesion in the cranial part of the intestine. Note cellular vacuolation (V), pycnosis (arrow), caryorrhexis (arrowhead) and immunolabelling. Scale bar $=5 \mu \mathrm{m}$. Fig. 18. Cross-section of the intestine adjacent to the liver anlage (L). In the developing muscularis focal immunolabelled lesions with cellular vacuolation (V) and pycnosis (arrowhead) are evident. Scale bar $=10 \mu m$. Fig. 19. Cranial part of the yolk sac (YS). The yolk-sac epithelium appears thickened and degenerate, with pale irregular nuclei (arrowheads). Immunolabelling was primarily found in these lesions. Scale bar $=50 \mu \mathrm{m}$. Fig. 20. Liver anlage. Note the multifocal lesions with pycnotic cells (arrowheads). Scale bar $=2 \mu \mathrm{m}$. Fig. 21. Cross-section of gill arches showing immunolabelling in the epithelium and in probable mesodermal cells. Scale bar $=10 \mu \mathrm{m}$. Fig. 22. Pectoral fin bud from larvae sampled on Day 26. Immunolabelling is prominent in the mesodermal tissue. Scale bar $=10 \mu \mathrm{m}$ 


\section{RT-PCR for nodavirus}

The RT-PCR amplification using total nucleic acids extracted from larvae challenged with infectious homogenate was positive and a single product of approximately 430 base pairs ( $\mathrm{T}_{4}$ region) was generated. Testing of larvae from mock- and unchallenged groups was negative.

\section{DISCUSSION}

This study demonstrates that Atlantic halibut yolksac larvae can be infected by nodavirus and develop VER after waterborne challenge under controlled laboratory conditions. This conclusion is supported by several lines of evidence. Following exposure to the infectious homogenate, a significant rise in cumulative mortality occurred compared to controls. A dose-response was demonstrated by a significant increase in the lengths of the incubation periods after 10-fold decreases in the doses of virus. Furthermore, the lesions observed in the virus-challenged groups were typical of VER and closely similar to those observed in natural outbreaks of the disease (Grotmol et al. 1997). Viriogenesis in the nervous tissue of challenged larvae was indicated by the presence of large numbers of nodavirus-like particles with an ultrastructural morphology identical to that of the virions of the infectious material. In addition, nodavirus antigens were detected in situ in nervous tissue and in several other organs by immunohistochemistry, and genomic RNA from nodavirus was redetected by RT-PCR in the larvae after challenge. Our results are thus in accordance with other studies that have concluded that waterborne transfer of nodavirus may occur in other species (Glazebrook et al. 1990, Mori et al. 1991, Arimoto et al. 1993, Nguyen et al. 1994, Tanaka et al. 1998).

The present study has also demonstrated that nodavirus are highly pathogenic at $6^{\circ} \mathrm{C}$, causing VER with $100 \%$ cumulative mortality. Previous studies have indicated that the virulence of nodavirus increases with a rise in rearing temperature (Arimoto et al 1993, Tanaka et al 1998). The high virulence of the Atlantic halibut nodavirus at $6^{\circ} \mathrm{C}$ may represent an adaptation to replication in cold-water fish and may thus be a phenotypic feature of this virus strain compared to nodavirus pathogenic to warmwater species. Phenotypic differences may be reflected by the genomic variation described among nodaviruses of Pacific and Mediterranean origin based on sequences of a variable region $\left(\mathrm{T}_{4}\right)$ of their coat protein genes (Nishizawa et al. 1997). Virus strains from cold-water species such as barfin flounder Verasper moseri and Pacific cod Gadus macrocephalus are genetically closely related (Nishizawa et al. 1997) and may represent other viruses adapted to replication in a cold environment.

The incubation period recorded in the present study ( $\left(\mathrm{T}_{50}\right.$ ranged from 14 and $32 \mathrm{~d}$ ) was dependent on the point of time of inoculation and on the dose of virus. In spite of postponement of the inoculation to Day 13, the outbreak of disease occurred simultaneously with the groups challenged immediately after hatching. This indicates that at least until Day 13 the susceptibility of the larvae to the present nodavirus strain was low, and also that no infection influencing mortality occurred before this point of time. The results of the immunohistochemistry supports this notion as no signs of infection could be detected before Day 18. These results imply that the Atlantic halibut larvae become susceptible to nodavirus between Days 13 and 18 . The possibility exists that if the larvae were challenged later in this interval the incubation period might have been even shorter than that observed in the present study. The underlaying mechanisms are possibly related to the differentiation of the nervous system. In the first period after hatching most of the CNS consists of undifferentiated glia and neurogenic cells, which may yet lack expression of viral receptors or other cytoplasmic factors essential to nodavirus replication. This view is supported by the observation that nodavirus were never detected by immunohistochemistry nor electron microscopy in cells of the growth zones in the brain and retina. Alternatively, the infection at an early stage may be impeded by for instance by lack of internalisation and routes for viral transport to the CNS. If axonal transport of virus is important in the pathogenesis the differentiation of the peripheral nervous system with outgrowth of axons may be of importance. A recent study of the ontogenesis of the Atlantic halibut CNS (Holmqvist et al. 1996) has indicated that the rate of differentiation of neurons and the formation of neuronal interconnections are at its peak in the same period as the disease manifested itself in the present study. Shorter incubation periods have been reported in previous studies on waterborne challenge with nodavirus on warmwater teleosts (Arimoto et al. 1993, Tanaka et al. 1998) and this may indicate that the low rearing temperature in the present study may also contribute to the prolongation of the incubation period. Further studies are needed to unravel all the underlying mechanisms triggering the replication of nodavirus in the yolk-sac larvae of the Atlantic halibut.

In spite of the immunolabelling in the intestine and other non-nervous tissues, we were unable with certainty to confirm the presence of virus in these tissues by electron microscopy. Infected cells are difficult to detect when present in low numbers or when they are focally distributed. Nodavirus are small $(25 \mathrm{~nm})$ and 
when they are present as single particles they are difficult to distingush from numerous other cytoplasmic components of similar size and shape. Morphological identification of nodavirus-like particles in the electron microscope is thus uncertain unless semicrystalline aggregates are detected.

In the present study, signs of viral replication in the stratified epithelium of the cranial region of the intestinal anlage occurred simultaneously with the initial infection of the CNS. The esophagus and cardiac stomach region has also been shown to be a possible portal of entry for infectious haematopoietic necrosis virus (IHNV) in juvenile rainbow trout Oncorhynchus mykiss and coho salmon $O$. kisutch (Helmick et al. 1995). In striped jack larvae replication of nodavirus occurred simultaneously in the epidermis and in the CNS (Nguyen et al. 1996) indicating one possible portal of entry into the larvae. The present study also indicates that nodavirus may replicate in stratified epithelia, and that these tissues may play a role in the pathogenesis of the infection.

In the CNS of the Atlantic halibut larvae, the initial major focus of immunolabelling was in the caudal brain stem. Immunolabelling was simultaneously observed in the stratified epithelium of the anterior intestine indicating a possible primary site of replication and a portal of entry. This region is exposed to virus in the water through the drinking activity of the larvae. The drinking takes place through a single gill opening from Day 2 increasing exponentially until Day 15 after hatching (Reitan et al. 1994). If the intestinal epithelium is one point of primary replication, the virus may reach the brain stem by axonal transport through cranial nerves such as the vagus nerves, which innervate the intestine from nuclei in the caudal brain stem. Such axonal transport from the peripheral nervous system to the CNS has been documented for other neurotropic viruses (Johnson 1982, Kristensson 1982). At later stages of the infection signs of viral replication were apparent in a number of tissues, and the possibility that these also may have been ports of entry cannot be excluded. The amount of virus present in these tissues at an early stage of infection may have been too low to be detected by the methods we employed.

In the model applied in the present study, each well constitutes an independent experimental unit that permits the rearing, challenge and monitoring of individual larva. Although high cumulative mortality also occurred in the control groups, these larvae showed none of the typical lesions of VER and nodavirus was not detected. The cause of mortality in these groups is difficult to determine. In the last part of the experiment, towards the start-feeding period, death due to starvation or accumulation of toxic substances may have contributed to the mortality.
Acknowledgements. The authors thank Hari Rudra, Ingrid Uglenes, Nina Ellingsen and Teresa Cieplinska for excellent technical assistance. We also thank Dr E. Biering for preparation of the antiserum and Dr B.K. Hjeltnes for providing excellent working facilities. This study was financed by the Research Council of Norway.

\section{LITERATURE CITED}

Anonymous (1995) Diseases of hatchery reared larvae and juveniles. Japan Sea-Farming Association, Kyokai Kenkyu Shiryo 66 (in Japanese)

Arimoto M, Mori K, Nakai T, Muroga K, Furusawa I (1993) Pathogenicity of the causative agent of viral nervous necrosis disease in striped jack, Pseudocaranx dentex. J Fish Dis 16:461-469

Bellance R, Gallet de Saint-Aurin D (1988) L'encéphalite virale du loup de mer. Caraibes Medical, p 105-144

Bergh $\varnothing$. Hansen GH, Taxt RE (1992) Experimental infection of eggs and yolk-sac larvae of halibut, Hippoglossus hippoglossus L. J Fish Dis 15:379-391

Bloch B, Gravningen K, Larsen JL (1991) Encephalomyelitis among turbot associated with a picornavirus-like agent. Dis Aquat Org 10:65-70

Boonyarathpalin S, Supamattaya K, Kasornchandra J, Hoffmann RW (1996) Picorna-like virus associated with mortality and spongious encephalopathy in grouper Epinephelus malabaricus. Dis Aquat Org 26:75-80

Comps M, Pepin JF, Bonami JR (1994) Purification and characterization of two fish encephalitis virus (FEV) infecting Lates calcarifer and Dicentrarchus labrax. Aquaculture 123:1-10

Danayadol Y, Direkbusarakom S, Supamattaya K (1995) Viral nervous necrosis in brownspotted grouper, Epinephelus malabaricus, cultured in Thailand. In: Shariff $M$, Arthus JR, Subasinghe RP (eds) Diseases in Asian aquaculture II Fish Health Section, Asian Fisheries Society, Manila, p 227-233

Delsert C, Morin N, Comps M (1997) Fish nodavirus lytic cycle and semipermissive expression in mammalian and fish cell cultures. J Virol 71(7):5673-5677

Evensen $\varnothing$ (1993) An immunohistochemical study on the cytogenetic origin of pulmonary multinucleate giant cells in porcine dermatosis vegitans. Vet Pathol 31:162-170

Frerichs GN, Rodger HD, Peric Z (1996) Cell culture isolation of piscine neuropathy nodavirus from juvenile sea bass, Dicentrarchus labrax. J Gen Virol 77:2067-2071

Fukuda Y, Nguyen H D, Furuhashi M, Nakai T (1996) Mass mortality of cultured sevenband grouper, Epinephelus . septemfasciatus, associated with viral nervous necrosis. Fish Pathol 31:165-170

Glazebrook JS, Heasman MP, de Beer SW (1990) Picorna-like viral particles associated with mass mortalities in larval barramundi, Lates calcarifer Bloch. J Fish Dis 13:245-249

Grotmol S, Totland GK, Thorud K, Hjeltnes BK (1997) Vacuolating encephalopathy and retinopathy associated with a nodavirus-like agent: a probable cause of mass mortality of cultured larval and juvenile Atlantic halibut Hippoglossus hippoglossus. Dis Aquat Org 29:85-97

Helmick CM, Bailey FJ, LaPetra S, Ristow S (1995) The esophagus/cardiac stomach region: site of attachment and internalization of infectious hematopoietic necrosis virus in challenged juvenile rainbow trout Oncorhynchus mykiss and coho salmon O. kisutch. Dis Aquat Org 23:189-199

Holmqvist BI, Forsell J, Helvik JV (1996) Patterns of embryonic development of the brain and sensory organs studied 
in three marine teleost species. Soc Neurosci Abstr 22:395

Hsu SM, Raine L, Fanger $H$ (1981) Use of an avidin-biotinperoxidase complex (ABC) in immunoperoxidase techniques: a comparison between $\mathrm{ABC}$ and unlabelled antibody (PAP) procedures. Cytochemistry 29:577-580

Johnson RT (1982) Viral infections of the nervous system. Raven Press, New York

Kristensson K (1982) Implications of axoplasmic transport for the spread of viruses in the nervous system. In: Weiss DG, Gorio A (eds) Axoplasmic transport in physiology and pathology. Springer-Verlag, Berlin, p 153-158

Le Breton A, Grisez L, Sweetman J, Ollevier F (1997) Viral nervous necrosis (VNN) associated with mass mortalities in cage-reared sea bass, Dicentrarchus labrax (L.). J Fish Dis 20:145-151

Mori K, Nakai T, Nagahara M, Muroga K, Mekuchi T, Kanno $T$ (1991) A viral disease in hatchery-reared larvae and juveniles of redspotted grouper. Fish Pathol 26:209-210

Mori K, Nakai T, Muroga K, Arimoto M, Mushiake K, Furusawa I (1992) Properties of a new virus belonging to Nodaviridae found in larval striped jack (Pseudocaranx dentex) with nervous necrosis. Virology 187:368-371

Munday BL, Nakai T (1997) Special topic review: nodaviruses as pathogens in larval and juvenile marine finfish. World $J$ Microbiol Biotechnol 13:375-381

Munday BL, Langdon JS, Hyatt A, Humphrey JD (1992) Mass mortality associated with a viral-induced vacuolating encephalopathy and retinopathy of larval and juvenile barramundi, Lates calcanfer Bloch. Aquaculture 103:197-211

Nguyen HD, Mekuchi $T$, Imura $K$, Nakai $T$, Nishizawa $T$, Muroga K (1994) Occurrence of viral nervous necrosis (VNN) in hatchery-reared juvenile Japanese flounder Paralichthys olivaceus. Fish Sci 60:551-554

Nguyen HD, Nakai T, Muroga K (1996) Progression of striped jack nervous necrosis virus (SJNNV) infection in naturally and experimentally infected striped jack Pseudocaranx dentex larvae. Dis Aquat Org 24:99-105

Editorial responsibility: Jo-Ann Leong.

Corvallis, Oregon, USA
Nishizawa T, Mori K, Nakai T, Furusawa I, Muroga K (1994) Polymerase chain reaction (PCR) amplification of RNA of striped jack nervous necrosis virus (SJNNV). Dis Aquat Org 18:103-107

Nishizawa $T$, Furuhashi $M$, Nagai $T$, Nakai $T$, Muroga $K$ (1997) Genomic classification of fish nodaviruses by phylogenetic analysis of the coat protein gene. Appl Environ Microbiol 63(4):1633-1636

Petrusz P (1983) Essential requirements for the validity of immunocytochemical staining procedures. $J$ Histochem Cytochem 31:177-179

Pittman K, Bergh Ø, Opstad I, Skiftesvik AB, Skjolddal L, Strand $H(1990)$ Development of eggs and yolk sac larvae of halibut (Hippoglossus hippoglossus L.) J Appl Ichthyol $6: 142-160$

Reitan KI, Bolla S, Olsen Y (1994) A study of the mechanism of algal uptake in yolk-sac larvae of Atlantic halibut (Hippoglossus hippoglossus L.) J Fish Biol 44: 303-310

Song ZR, Kanai K, Yoshikoshi K, Niiyama H, Honda A, Ura K (1997) Mass mortalities of hatchery-reared larvae and juveniles of bartail flathead, Platycephalus indicus associated with viral nervous necrosis. Suisanzoshoku 45(2): 241-246

Tanaka S, Aoki H, Nakai T (1998) Pathogenicity of the nodavirus detected from diseased sevenband grouper Epinephelus septemfasciatus. Fish Pathol 33(1):31-36

Thiery R, Peducasse S, Castric J, Le Ven A, Jeffroy J, Baudin Laurencin F (1997) Experimental transmission of viral encephalopathy and retinopathy to juvenile sea bass ( $D i$ centrarchus labrax). Bull Eur Assoc Fish Pathol 17(3/4): $118-122$

Yoshikoshi K, Inuoe K (1990) Viral nervous necrosis in hatchery-reared larvae and juveniles of Japanese parrot-fish, Oplegnathus fasciatus (Temminck \& Schlegel). J Fish Dis 13:69-77

Zar JH (1984) Biostatistical analysis, 2nd edn. Prentice-Hall Inc., Engelwood Cliffs, NJ

Submitted: September 3, 1998; Accepted: January 20, 1999 Proofs received from author(s): May 5, 1999 